\title{
Impact of Critical Risks on the Major Constraints of Small Engineering Projects
}

\author{
Syed Hassan Raza ${ }^{1 a}$, Rameez Khalid², Muhammad Wasif ${ }^{1 b}$ \\ RECEIVED ON 31.01.2019, ACCEPTED ON 26.11.2019
}

\begin{abstract}
In this research, generic and specific risks related to the critical activities of the engineering projects are identified. The surveys and interviews from various project managers and engineers of the leading consultant firms conducting engineering projects in Pakistan are the core identifiers. Specific risks associated with the common engineering projects are qualitatively analyzed to prioritize the risks according to their impact on the schedule and cost of the project. Critical activities related to the specific risks are identified. Estimated manhours without and with quantitative risk assessment have been determined to study the impact of including risk analysis on the schedule and cost of the engineering projects. The relationship between the critical activities and the total man-hours have also been developed to identify the most critical activity or activities influencing the man-hours and ultimately the cost of the project. The likelihood of occurrence of risks are also related to the man-hour completion, to analyze the effect of certainty of the man-hour's determination, which is an important aspect of estimating schedule, EMV and finally cost. Using the analysis, it has been inferred that the 95\% confidence level is not suitable all the time for the estimation of risk impact on the schedule and cost. It increases the man-hour estimation resulting in less competitive proposal to win the project.
\end{abstract}

Keywords: Risk Management, Qualitative Risk Management, Quantitative Risk Management, Severity, Likelihood, Monte Carlo Simulation.

\section{INTRODUCTION}

$\mathrm{P}$ roject risk is an uncertain event or condition that, if it occurs, has a positive or negative effect on one or more project objectives such as scope, schedule, cost, and quality [1]. However, when the environmental threats and internal weaknesses overlap, a negative risk is occurred [2]. It can also be defined as the potential of the realization of unwanted, negative consequences of an event [3]. Perception of risk is not only subjective but is also time dependent and the sources through which information about risk is obtained [4]. Risk is divided into Internal (present within a project's life cycle) and External (present in a specific region, due to external factors) $[5,6]$. Project Risk Management includes the processes of conducting risk management planning, identification, qualitative and quantitative analysis, response planning, response implementation and controlling risk on a project [1]. For contractors, Risk Management is essential to minimize the losses and eventually get profit. It is argued that risk management at the early stages of the project is a critical factor in the success of the project. Identification of and management of risks are essential for business success since it is a proactive approach to avoid uncertainties [7]. Management of external risks is difficult since there is not enough initial data available and many

\footnotetext{
${ }^{1}$ Department of Industrial and Manufacturing Engineering, NED University of Engineering and Technology, Karachi, Sindh, Pakistan. Email: ${ }^{b}$ wasif@ neduet.edu.pk (Corresponding Author)

${ }^{2}$ Department of Management, Institute of Business Administration (IBA), Karachi, Pakistan. Email: rameezkhalid@iba.edu.pk
}

This is an open access article published by Mehran University of Engineering and Technology, Jamshoro under CC BY 4.0 International License. 
uncertainties are present [6]. It is worth understanding the difference between management of risk and management with risk [8]. Qualitative Risk Analysis is the process of prioritizing risks for further analysis or action by assessing and combining their probability of occurrence and impact. The key benefit of this process is that it enables project managers to reduce the level of uncertainty and to focus on high-priority risks. Quantitative Risk Analysis is the process of numerically analyzing the effect of identified risks on overall project objectives. The key benefit of this process is that it produces quantitative risk information to support decision making in order to reduce project uncertainty [1].

A semi quantitative analysis may be carried out for general risks, but a more quantitative risk analysis is required for technical risks. Risk due to human errors cannot be quantified due to failure data which is obtained and have human error. Hence, qualitative risk techniques may be preferred for human risks analysis [8].

Managers mostly use qualitative techniques in the form of judgment, gut feeling and intuition. Sometimes, it is just restricted to checklist only. After judgment, sensitivity analysis is mostly used. Quantitative and computational risk techniques are not commonly used mainly because of unawareness, unavailability of data and time constraint. Even though these quantitative techniques are not practical at times, however, they can still be used in more complex risky situations [7,9]. A research on risk analysis techniques in proposal assessment is presented by Hull [10]. Another research shows a practical example of quantitative risk management technique for a construction industry [11]. Monte Carlo technique can simultaneously consider both threats and opportunities and can select various probabilities for different criteria in an unbiased manner. Although, Monte Carlo may consider certain uncertainties which are not possible to occur in the real world [12]. However, it is still the mostly commonly used technique for simulation [1]. Yang gives an example of use of Monte Carlo Simulation in Information System Project Performance [13]. Tezukka applied Monte Carlo simulation for financial risk management [14].
Marseguerra optimized maintenance and repair polices using Monte Carlo Simulation [15].

Many local and multinational project-based firms in Pakistan follows strict and accurate procedures and framework of Project Management (PM) for all big and small projects. However, before the award of the projects during Proposal Stage, some critical factors for the success of the project are not considered which impact directly on the project. Risk Management (RM) is among such factors often neglected or is not given due importance [16]. Firms in which Qualitative RM techniques are used, the expertise on the Quantitative RM are not sufficient [16]. This results in failing to meet the schedule and/or cost during the implementation or execution phase of the project.

Risk Management process is extensively described in the literature available from various sources. However, there are quite a few aspects of RM still unknown for an economy as sensitive as Pakistan. Secondly, there are various papers on risk management but not much on actual use of risk management for practical purposes [17-25]. The purpose of this research is to focus on comparing the cost and schedule estimated for a sample project before and after the use of risk management techniques (both qualitative and quantitative).

This research article is divided into five major portions; the first section presents the introduction and literature review related to the research problem. Second section describe the background and methodology of qualitative and quantitative analysis applied on the identified risks. In Section 3, categorization and identification of generic and specific risks, which are most critical in the engineering projects in Pakistan are highlighted, along with their possible impacts on a project. Section 4 describes the quantitative analysis of the specific risk and their impact on the estimation of project manhours. Impact of the risks obtained in Section 3, is quantified by means of Monte Carlo Simulation and analysis of certainty is also performed in this section. The last section presents the meaningful conclusions deduced from this practical application of Quantitative Risk Management. 


\section{METHODOLOGY}

CLIENT is the leading plastic film manufacturer of the country, whereas CONSULTANT is one of the leading engineering project firm in the country. Usually, when a CLIENT contacts a CONSULTANT about a problem, which in turn creates a project prospect, the engineering division of CONSULTANT estimate the time required to complete the project and specially the critical activities based on "Man-Hour Estimation". The engineering division then forwards the estimated man hours for the critical activities to the business division. In practical, to make a competitive bid, the business department reduces the estimated man hour of critical activities as much as they can. At this point, a meeting is held between the engineering and business division and a final total man hour is agreed. Once the man hours are finalized, the business department computes the price rate of each man hour, puts a profit margin (the percentage of which is confidential and depends upon project size and stakeholder's perspective) and quotes the obtained cost to the CLIENT. Note that for commercial purposes, price is quoted instead of the man hours.

In a project, CLIENT installed Thermal Oil Heater and its piping network, which is experiencing excess deformation problem in its piping system of pump suction and discharge lines. Due to this deformation, their new plant has stopped production. For this reason, it is intended to cater these deformations by providing an optimum solution. Scope of work of CONSULTANT is to perform stress analysis for the said suction and discharge lines and suggest modifications. CLIENT wants to get this issue solved as soon as possible since they are only relying on the production of their old plant since their new plant is on shutdown. Due to the loss of production, the higher management of CLIENT exerted additional pressure which consequently gets transferred to CONSULTANT.

To carry the job, scope statement and WBS are generated to perform the project work. Project engineers are asked to list down the work-packages and activities that will be required to execute the job. Sequencing of activities are performed to develop the network diagram and the path with largest and critical activities have been identified. To a typical small-scale project as defined above, activities were listed with most likely time required to complete the job. Expert Judgment and Analogous Estimating are used as estimating techniques. These techniques are frequently used in practical fields since these are less costly and less time consuming, however, these are also inaccurate [1]. Both the techniques give a single point estimate, where the span and uniqueness of activities cause deviations. Table 1 presents the critical activities along with the time computed by the engineering division and the business division. After a meeting between engineering and business division, the final man hours decided were 85 . The price quoted to the CLIENT was based on total of 85 man-hours. For confidentiality purpose, the study of this case will be in terms of man hours rather than the price quoted to the client. The cost was eventually accepted by CLIENT and the project was won.

Table 1: Estimated Man-Hour Estimate of Critical Activities

\begin{tabular}{|c|c|c|c|}
\hline \multirow{2}{*}{$\begin{array}{c}\text { S. } \\
\text { No. }\end{array}$} & Activities & \multicolumn{2}{c|}{ Man Hours } \\
\cline { 3 - 4 } & $\begin{array}{c}\text { Engineering } \\
\text { Division }\end{array}$ & $\begin{array}{c}\text { Business } \\
\text { Division }\end{array}$ \\
\hline 1 & Data Collection & 24 & 16 \\
\hline 2 & $\begin{array}{c}\text { Modeling of Suction Line } \\
\text { on a simulation software }\end{array}$ & 12 & 8 \\
\hline 3 & $\begin{array}{c}\text { Modeling of Discharge } \\
\text { Line on a simulation } \\
\text { software }\end{array}$ & 12 & 8 \\
\hline 4 & $\begin{array}{c}\text { Analysis of Suction Line } \\
\text { on a simulation software }\end{array}$ & 16 & 12 \\
\hline 5 & $\begin{array}{c}\text { Analysis of Discharge } \\
\text { Line on a simulation } \\
\text { software }\end{array}$ & 16 & 12 \\
\hline 6 & $\begin{array}{c}\text { Preparation of Stress } \\
\text { Report of Suction Line }\end{array}$ & 12 & 8 \\
\hline 7 & $\begin{array}{c}\text { Preparation of Stress } \\
\text { Report of Discharge Line }\end{array}$ & 12 & 72 \\
\hline & Total Man Hour & 104 & \\
\hline
\end{tabular}

Note that, this exercise was done without any risk management and certain critical risk factors were ignored from the man hour estimation by both engineering and business division. Those factors became apparent in the execution phase of the project. As a result, the project was eventually completed in 135 hours. This consequently resulted in a loss of 50 man-hours. This loss in 50 hours affected the profit margins, which were kept in the initial calculations when duration was decided for the project (85 manhours). Secondly, it resulted in the delay of the schedule of the project, which consequently resulted 
in the delayed production on CLIENT's end and a significant loss. Thirdly, it created a bad image of CONSULTANT in the market.

To overcome these deviations on future projects, a research work has been conducted and man hours are estimated again by incorporating risk management in the process. To identify risks and carry out the qualitative analysis, a research methodology is devised. This time, experienced project managers and engineers in the CONSULTANT firm were asked; to get an overall view of the possible risks on the project, develop risk categories, prepare a Risk Breakdown Structure (RBS) and identify the risk variables which are most critical for these types of project. Once RBS is formed and individual risks are identified for the similar projects, qualitative and quantitative analysis are performed. Based on qualitative analysis, critical risks are sorted out and quantitative assessment is performed. Using the quantitative assessments, regression analysis is carried out to relate the risk variables with the man-hours of the project. Finally using the PERT techniques, man-hours for the completion of projects are estimated. The estimated man-hours using the risk management techniques are compared with the estimated man-hours without the risk management technique.

\section{RISK IDENTIFICATION AND QUALITATIVE ASSESSMENT}

Identifying common risks are more qualitative in nature, hence a survey is conducted as a research tool. Among many methods available for survey, questionnaire-interview duo was used as it is the most common and reliable method available [26]. To make sure that the collection of data is accurate, the results were gathered from everyone separately. The precision of data is directly proportional to the number of sample [19]. Keeping this in view, complete population of Project Managers experiencing the Engineering, Procurement and Construction (EPC) projects, in one of the leading firms of Pakistan in the project industry were considered to provide risk inputs. Three questions were asked from each participant:

(a) Identify the risk categories (b) Identify all possible risks related to the risk categories

(c) Impact and likelihood of identified risks on project (Qualitative Assessment)

All the project managers had post-graduate qualification in the field of engineering and management sciences with an average of more than 13 years of experience. It is safe to assume that the results obtained are meaningful and applicable to the industry under discussion.

Categorization of Risks: For the defined projects, Risk Breakdown Structure (RBS) is formed with the identified risk categories (or sources). It is a hierarchical representation of risks according to their risk categories. RBS helps the project team to look at many sources from where project risk may arise in a risk identification exercise [3]. Broadly, risk can be classified into two types: internal risks - present within the lifecycle of the project, and external risks present in the region in which the project is taking place [6]. Zhi made two generic classifications for each internal and external risk [8].

The findings of the first question of the interview (regarding the formation of risk classes) are compiled and presented as either Internal or External risk in Fig 1. Here a number with one decimal digit represents the Risk Breakdown Structure Number or simply RBS No.

Identification of Risk: Many risks have been identified over the period of time, but for a region with high uncertainty like Pakistan, very little literature about the risk assessment have been found. Due to this reason, the risks faced by Pakistani Engineering Project Industry are complied. Based on the categories defined in Fig 1, a huge list of project risks was developed. It includes 129 internal risks and 55 external risk. Table 2 provides the numbers risks identified in each category defined in the Fig 1.

Since, the list of potential risks is rather long, it is not practical to list all risks here. Few sample risks identified during this process are presented in the Table 3. To get the specific risks associated with the EPC projects which are the subject of this research, risk identification is converged to the specific project

Mehran University Research Journal of Engineering and Technology, Vol. 40, No. 2, April 2021 [p-ISSN: 0254-7821, e-ISSN: 2413-7219] 


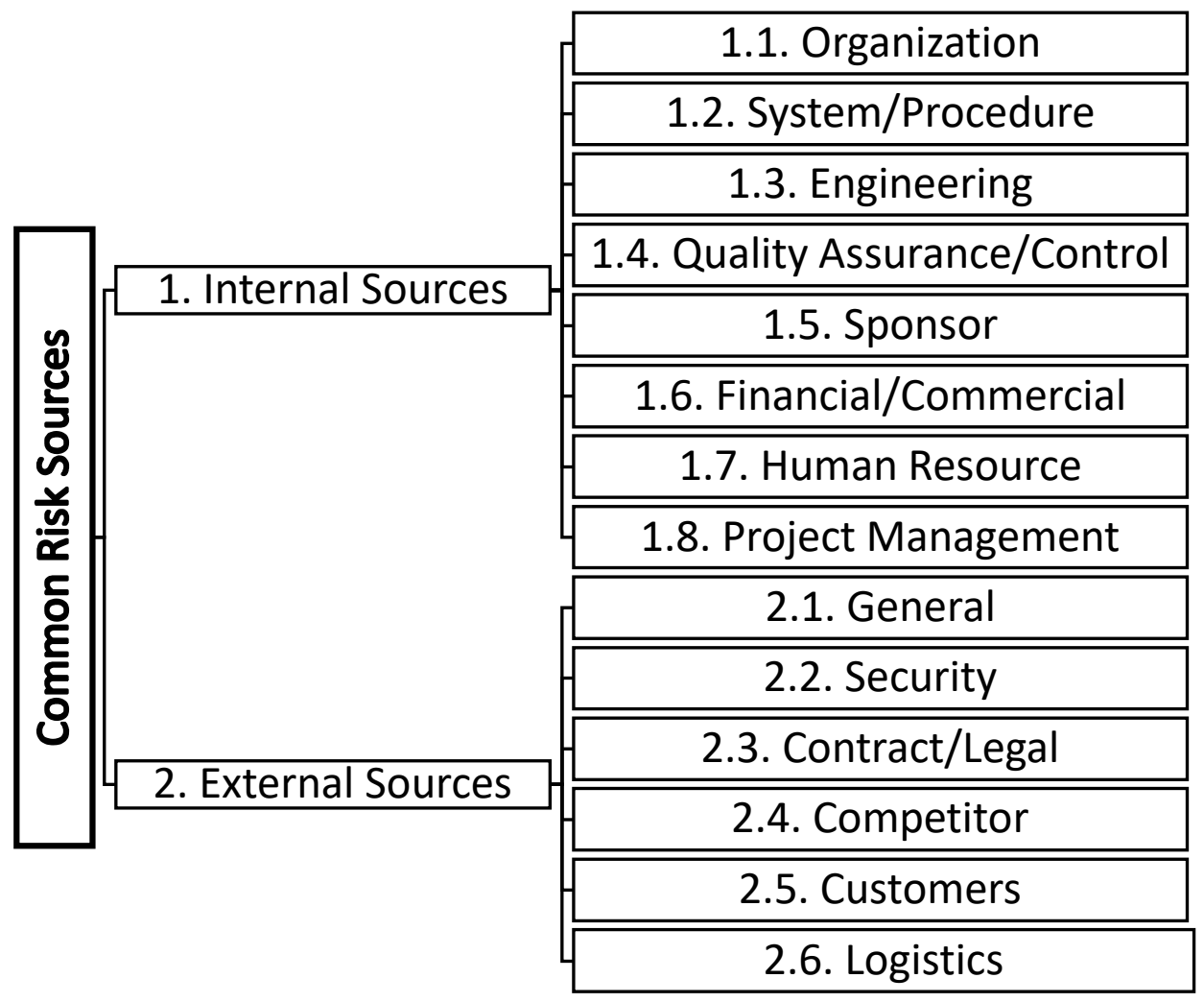

Fig. 1: Common Risk Sources and their Classification

\begin{tabular}{|c|c|c|}
\hline \multicolumn{3}{|c|}{ Table 2: Number Of Generic Risks } \\
\hline $\begin{array}{c}\text { RBS } \\
\text { No. }\end{array}$ & Risk Category & $\begin{array}{c}\text { No. of Risks } \\
\text { Identified }\end{array}$ \\
\hline 1.1 & Organization & 06 \\
\hline 1.2 & System/Procedure & 07 \\
\hline 1.3 & Engineering & 25 \\
\hline 1.4 & Quality Assurance/Control & 11 \\
\hline 1.5 & Sponsor & 03 \\
\hline 1.6 & Financial/Commercial & 18 \\
\hline 1.7 & Human Resource & 13 \\
\hline 1.8 & Project Management & 46 \\
\hline & Total Internal Risks & 129 \\
\hline 2.1 & General & 14 \\
\hline 2.2 & Security & 06 \\
\hline 2.3 & Contract/Legal & 06 \\
\hline 2.4 & Competitors & 05 \\
\hline 2.5 & Customers & 14 \\
\hline 2.6 & Logistics & 10 \\
\hline & Total External Risks & 55 \\
\hline & Total Identified Risks & 184 \\
\hline
\end{tabular}

manager and engineers who worked in the similar kind of projects. Experienced project managers and engineers from the same pool are shortlisted. Interview and Survey Questionnaires are used to gather the specific project risks which are most critical for the projects and are caused by the identified sources of risk. Specific risks associated with the risk source within the projects critical activities are identified by the project managers and engineers. A sample of the five specific risks related to the type of projects, found redundant in the survey and interviews are listed in the Table 4. Here the specific RBS numbers related to the projects are numbered with ' $\mathrm{S}$ ' as prefix.

Risk Analysis (Qualitative Assessment): The impact and probability of these activities are identified in the qualitative analysis so that risk priority can be determined, and the activities can be segregated based on their priority. Here risk priority can be measured through the Risk Priority Number (RPN) [27]:

$$
\text { RPN }=\text { Impact } \times \text { Liklihood }
$$

where, Impact and likelihood are quantified by a magnitude on Linkert Scale of 1 to 5 using a defined scale. This scale of impact and likelihood are used by 


\begin{tabular}{|c|c|c|c|}
\hline \multicolumn{4}{|c|}{$\begin{array}{r}\text { Table 3: Sample of Identified Major } \\
\text { Risks and their Sources }\end{array}$} \\
\hline $\begin{array}{l}\text { RBS } \\
\text { No. }\end{array}$ & Risk & Source & Stakeholder \\
\hline 1.4 .1 & $\begin{array}{l}\text { Passing Quality Test is a } \\
\text { major Criteria for success }\end{array}$ & Internal & Quality \\
\hline 1.7.1 & $\begin{array}{c}\text { Labor skill are not } \\
\text { favorable for the project } \\
\text { environment }\end{array}$ & Internal & $\begin{array}{l}\text { Human } \\
\text { Resource }\end{array}$ \\
\hline 1.7 .2 & $\begin{array}{l}\text { Absentism and shortage of } \\
\text { labour due to contract- } \\
\text { based jobs }\end{array}$ & Internal & $\begin{array}{l}\text { Human } \\
\text { Resource }\end{array}$ \\
\hline 1.7.3 & $\begin{array}{c}\text { Training of labour and } \\
\text { management needed are } \\
\text { expensive and unavailable }\end{array}$ & Internal & $\begin{array}{l}\text { Human } \\
\text { Resource }\end{array}$ \\
\hline 1.8 .1 & $\begin{array}{l}\text { Risk Management is } \\
\text { applicable from the } \\
\text { bidding stage (starting) to } \\
\text { completion of the project } \\
\text { (ending) }\end{array}$ & Internal & $\begin{array}{c}\text { Project } \\
\text { Management }\end{array}$ \\
\hline 1.8 .2 & $\begin{array}{l}\text { Internal risks affect the } \\
\text { project in terms of cost } \\
\text { overrun, schedule delay } \\
\text { and/or quality issues. }\end{array}$ & Internal & $\begin{array}{c}\text { Project } \\
\text { Management }\end{array}$ \\
\hline 2.5 .1 & $\begin{array}{l}\text { Product scope is not well } \\
\text { defined by the Sponsor }\end{array}$ & External & Customer \\
\hline 2.5 .2 & $\begin{array}{l}\text { Acceptance Criterion for } \\
\text { the project deliverables are } \\
\text { conflicting }\end{array}$ & External & Customer \\
\hline 2.5 .3 & $\begin{array}{l}\text { External risks affect in } \\
\text { terms of the stakes of the } \\
\text { project itself, along with } \\
\text { other intangible factors } \\
\text { like customer satisfaction, } \\
\text { market penetration and } \\
\text { good-will. }\end{array}$ & External & Customer \\
\hline 2.5 .4 & $\begin{array}{l}\text { Customer Satisfaction } \\
\text { impacts the good will and } \\
\text { market capturing for } \\
\text { future projects }\end{array}$ & External & Customer \\
\hline
\end{tabular}

\begin{tabular}{|c|c|c|c|c|}
\hline \multicolumn{5}{|c|}{ Table 4: Sample of Identified Specific Risks and } \\
their Sources \\
\hline $\begin{array}{c}\text { S.RBS } \\
\text { No. }\end{array}$ & Risk & $\begin{array}{c}\text { Generic } \\
\text { RBS No. }\end{array}$ & $\begin{array}{c}\text { Sourc } \\
\mathrm{e}\end{array}$ & Stakeholder \\
\hline S2.5.X & $\begin{array}{c}\text { Data provided } \\
\text { by CLIENT is } \\
\text { inaccurate }\end{array}$ & 2.5 & $\begin{array}{c}\text { Exter } \\
\text { nal }\end{array}$ & Customer \\
\hline S2.6.X & $\begin{array}{c}\text { Vendor Data } \\
\text { of Pumps is } \\
\text { not available }\end{array}$ & 2.6 & $\begin{array}{c}\text { Exter } \\
\text { nal }\end{array}$ & Logistics \\
\hline S1.4.X & $\begin{array}{c}\text { Piping not } \\
\text { passing in } \\
\text { Stress } \\
\text { Analysis }\end{array}$ & 1.4 & $\begin{array}{c}\text { Intern } \\
\text { al }\end{array}$ & QA/QC \\
\hline S2.1.X & $\begin{array}{c}\text { Law \& order } \\
\text { situation in } \\
\text { the city }\end{array}$ & 2.1 & $\begin{array}{c}\text { Exter } \\
\text { nal }\end{array}$ & General \\
\hline S1.7.X & $\begin{array}{c}\text { Attrition of } \\
\text { work force }\end{array}$ & 1.7 & $\begin{array}{c}\text { Intern } \\
\text { al }\end{array}$ & $\begin{array}{c}\text { Human } \\
\text { Resource }\end{array}$ \\
\hline
\end{tabular}

the project managers of the CONSULTANT and are provided in the Table 5 and 6.

\begin{tabular}{|c|c|}
\hline \multicolumn{2}{|c|}{ Table 5: Magnitude of Impact } \\
\hline Impact Type & Impact Magnitude \\
\hline $\begin{array}{c}\text { Non-compliance to QC or Customer or } \\
\text { Major Rework } \\
\text { Budget or schedule baseline exceed more } \\
\text { than 50\% }\end{array}$ & 2.00 \\
\hline $\begin{array}{c}\text { Observations of QC or Customer or } \\
\text { Rework } \\
\text { Budget or schedules baselines exceed up } \\
\text { to 50\% }\end{array}$ & 1.75 \\
\hline $\begin{array}{c}\text { Opportunity of Improvements in } \\
\text { deliverable or Minor rework } \\
\text { Budget or schedule baselines exceed up } \\
\text { to 30\% }\end{array}$ & 1.50 \\
\hline $\begin{array}{c}\text { No Rework } \\
\text { Budget or schedule baselines exceed up } \\
\text { to 20\% }\end{array}$ & 1.25 \\
\hline $\begin{array}{c}\text { No Rework } \\
\text { Budget or schedule baselines exceed up } \\
\text { to 5\% }\end{array}$ & 1.00 \\
\hline
\end{tabular}

\begin{tabular}{|c|c|}
\hline \multicolumn{2}{|c|}{ Table 6: Magnitude of Likelihood } \\
\hline Probability of Occurrence & Likelihood \\
\hline $\begin{array}{c}\text { Probability of occurrence is equal to or } \\
\text { more than 80\% }\end{array}$ & 1.0 \\
\hline $\begin{array}{c}\text { Probability of occurrence is less than 80\% } \\
\text { and more than 60\% }\end{array}$ & 0.8 \\
\hline $\begin{array}{c}\text { Probability of occurrence is less than 60\% } \\
\text { and more than 40\% }\end{array}$ & 0.6 \\
\hline $\begin{array}{c}\text { Probability of occurrence is less than 40\% } \\
\text { and more than 20\% }\end{array}$ & 0.2 \\
\hline $\begin{array}{c}\text { Probability of occurrence is equal to or less } \\
\text { than 20\% }\end{array}$ & \\
\hline
\end{tabular}

The Risk Priority Number classifies the risks into three categories, which are; High Priority Risk, Medium Priority Risk and Low Priority Risk. The classification is based on the combination of the impact and likelihood defined by the RPN Matrix shown in the Fig. 2. In this figure, if the RPN Number of a risk ranges from 0.2 to 0.5 , it will be taken as the low priority risk. In other case, if the RPN Number of a risk ranges more than 0.6 to 1.5 , it will be taken as medium priority risk. This type of risks has exception that, if any of the risk is rated with highest impact magnitude, i.e. 2.0, then it will not be treated as the medium priority risk, rather it will be taken as the high priority risk. Risks with the RPN Number greater than 1.5 will be taken as High Priority Risks.

Based on the past experiences and lesson learned from previous projects, project managers and engineers are asked to assign a probability (likelihood) to each risk along with the impact of the risk on the project, if the 


\begin{tabular}{|c|c|c|c|c|}
\hline \multicolumn{5}{|c|}{ Table 7: Risk Priority of Specific Risks } \\
\hline $\begin{array}{c}\text { RBS } \\
\text { No. }\end{array}$ & Impact & Likelihood & $\begin{array}{c}\text { Risk } \\
\text { Priority } \\
\text { Number } \\
\text { (RPN) }\end{array}$ & $\begin{array}{c}\text { Risk } \\
\text { Priority }\end{array}$ \\
\hline S2.5.X & 2.00 & 0.8 & 1.60 & High \\
\hline S2.6.X & 1.50 & 0.5 & 0.75 & Medium \\
\hline S1.4.X & 2.00 & 0.3 & 0.60 & Medium \\
\hline S2.1.X & 2.00 & 0.3 & 0.60 & Medium \\
\hline S1.7.X & 1.00 & 0.2 & 0.20 & Low \\
\hline
\end{tabular}

risk occurs. Table 7 gives the list of samples identified risk, their impact magnitude, likelihood, risk priority number and decided risk priority based on Risk priority matrix.

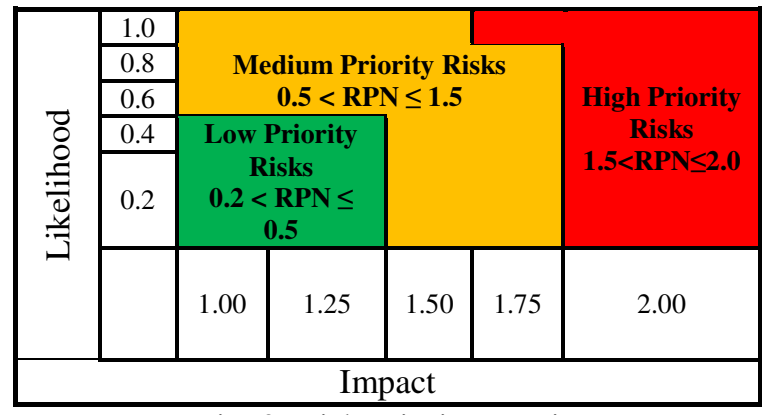

Fig. 2: Risk Priority Matrix

\begin{tabular}{|c|c|}
\hline \multicolumn{2}{|c|}{ Table 8: Critical Activities Related to the Specific } \\
Risks
\end{tabular}

It can be seen from the Table 7 that the risk with the RBS No. S1.7.X has the low risk priority, hence based on the action decided for the low priority risk, the risk has been monitored and no control has been assigned to this risk. For the high and medium priority risk, the quantitative analysis will be performed by considering the critical activities related to the project.

\section{QUANTITATIVE ANALYSIS}

Once the risks on critical activities have been identified and prioritized, the next step is to perform quantitative analysis. Quantitative Assessment has been performed on the activities related to the high and medium priority risk. Table 8 enlist the critical activities of the project and their relationship with the sample specific risks.

Monte Carlo Simulation has been applied on the quantitative assessment using the Oracle's Crystal Ball Software. Crystal Ball is a MS-Excel plugin tool used for forecasting, risk analysis and optimization [13]. To use Crystal Ball, a model has been built for which a technique of estimation is required, because each uncertain parameter within the model is represented by a probability distribution [27]. The estimation technique being used is Three-pointEstimating, which significantly improves the accuracy of determination as compared to single point estimates [1]. In three-point-estimating, the activity duration associated with the specific risks are considered as most likely, optimistic and pessimistic. Depending upon the distribution of values within the range defined above, the formula relevant of that distribution will be used to make the estimates. Although, it is not necessary to consume time on the precision of probability distribution since the result is significantly insensitive to the type of distribution being used [27]. However, for most practical purpose Beta and Triangular distributions are frequently used [1]. One of the reasons is that the Beta or Triangular distributions (which are non-parametric distributions) are easy to experts or practitioners to interpret and draw conclusions [27]. Among the two, distributions, triangular distribution is preferred for the modeling expert's opinion [27].

In this case, the three-point-estimate of project duration, the Triangular Distribution is used, where each point specifies the duration as mentioned below;

(a) Optimistic Time - $\mathrm{T}_{\mathrm{o}}$ (estimations by Business Division),

(b) Most Likely Time - $\mathrm{T}_{\mathrm{m}}$ (estimations by Engineering Division) and

(c) Pessimistic Time - $T_{p}$ (estimations considering the involvement of risk).

Expert's opinion (Engineering Division) is used to establish a relationship between each risk and an activity. That is the Pessimistic Time - $\mathrm{T}_{\mathrm{p}}$ is calculated using the relation involving the risk priority number of the risk using the relation: 
$\mathrm{T}_{\mathrm{p}}=\mathrm{T}_{\mathrm{m}}+\mathrm{T}_{\mathrm{m}} \cdot$ RPN

Estimated time for each activity related to the high and medium risks can be determined using the Triangular Distribution [27]:

$\mathrm{T}_{\mathrm{est}}=\frac{\mathrm{T}_{0}+\mathrm{T}_{\mathrm{m}}+\mathrm{T}_{\mathrm{p}}}{3}$

Variance of the estimated time of the activities are calculated using the relations [27];

$\sigma_{\mathrm{T}}=\frac{\left(\mathrm{T}_{0}\right)^{2}+\left(\mathrm{T}_{\mathrm{m}}\right)^{2}-\mathrm{T}_{0} \cdot \mathrm{T}_{\mathrm{m}}-\mathrm{T}_{0} \cdot \mathrm{T}_{\mathrm{p}}-\mathrm{T}_{\mathrm{m}} \cdot \mathrm{T}_{\mathrm{p}}}{18}$

Table 9 gives the pessimistic time calculated using equation (2), estimated time and standard deviation for each activity related to high and medium risk. RBS number of the risks are also mentioned with the activities shown in the Table 9.

\begin{tabular}{|c|c|c|c|c|}
\hline \multicolumn{2}{|c|}{ Table 9: Pessimistic Time of Critical Activities } \\
\cline { 2 - 5 } Activity No. & $\begin{array}{c}\text { Optimistic } \\
\left.\text { Time ( } \mathrm{T}_{\mathrm{o}}\right)\end{array}$ & $\begin{array}{c}\text { Most } \\
\text { Likely } \\
\text { Time } \\
\left(\mathrm{T}_{\mathrm{m}}\right)\end{array}$ & $\begin{array}{c}\text { Risk } \\
\text { Priority } \\
\text { No. } \\
\text { (RPN) }\end{array}$ & $\begin{array}{c}\text { Pessimistic } \\
\text { Time }\left(\mathrm{T}_{\mathrm{p}}\right)\end{array}$ \\
\hline $\begin{array}{c}\text { Data } \\
\text { Collection } \\
\text { (S2.5.X) }\end{array}$ & 16 & 24 & 1.6 & 62.4 \\
\hline $\begin{array}{c}\text { Modeling of } \\
\text { Suction Line } \\
\text { (S2.6.X) }\end{array}$ & 8 & 12 & 0.75 & 21.0 \\
\hline $\begin{array}{c}\text { Modeling of } \\
\text { Discharge } \\
\text { Line } \\
\text { (S2.6.X) }\end{array}$ & 8 & 12 & 0.75 & 21.0 \\
\hline $\begin{array}{c}\text { Analysis of } \\
\text { Suction Line } \\
\text { (S1.4.X) }\end{array}$ & 12 & 16 & 0.6 & 25.6 \\
\hline $\begin{array}{c}\text { Analysis of } \\
\text { Discharge } \\
\text { Line } \\
\text { (S1.4.X) }\end{array}$ & 12 & 16 & 0.6 & 25.6 \\
\hline $\begin{array}{c}\text { Stress Report } \\
\text { of Suction } \\
\text { Line }\end{array}$ & 8 & 12 & -- & 19.2 \\
\hline $\begin{array}{c}\text { Stress Report } \\
\text { of Discharge } \\
\text { Line }\end{array}$ & 8 & 12 & -- & 19.2 \\
\hline $\begin{array}{c}\text { Total Man } \\
\text { Hours }\end{array}$ & 72 & 104 & & 194.0 \\
\hline & & & & \\
\hline
\end{tabular}

To forecast the number of man-hours required to complete the work on critical path, Monte Carlo Simulation has been applied in the Oracle's Crystal Ball Software with 1000 trials. For most practical purposes, 1000 trails are is used since it is a statistically significant number of random variables [3]. Confidence level is initially set to $95 \%$, which is a common benchmark to estimate the time and cost using the three-point estimate. However, it will be changed in order to make reasonable deductions. Another input worth noticing is the choice of Extreme Speed as Run Mode. Crystal Ball performs a speed comparison. For this problem, there was no difference in output with either extreme speed or normal speed has been observed, hence extreme speed is used. Total running time of simulation was 0.31 seconds, with an average of 3,100 trials/seconds and 22,400 random numbers generated per seconds. To study the relationship between the man-hours and critical activities, correlation between the total man-hours and the estimated time for each activity are also analyzed. Fig. 3 to Fig. 5 presents the correlation between the total man-hour and three critical activity. The value of correlation of "Data Collection" is 0.842 , which shows that this activity is directly related to total man-hour. However, other activities have weak correlation around 0 , showing that they have little or no relationship with the total man hour. This can also be observed in the Fig. 3, where scatter plot of random variables for "Data Collection" is very close to the direct relationship straight line, while in Fig. 4 and Fig. 5 for "Modeling of Suction Line" and "Stress Report of Suction Line" the estimated time by random variables are scattered. Table 10 presents the critical activities and their contribution to variance in the determination of total man-hours along with the correlation constant.

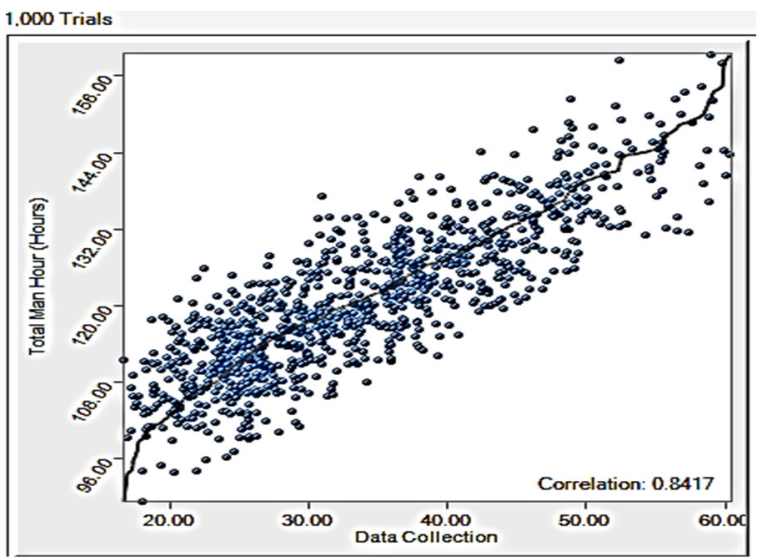

Fig. 3: Correlation between data collection and Total Man Hours 


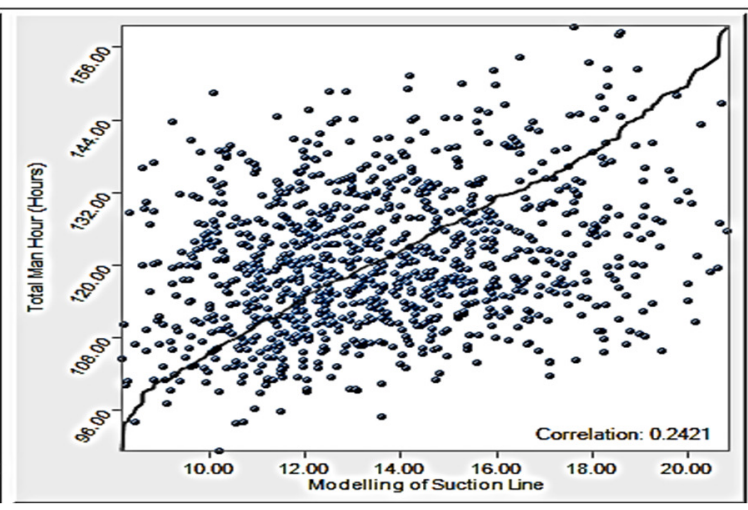

Fig. 4: Correlation between Modeling of Suction Line and Total Man Hours

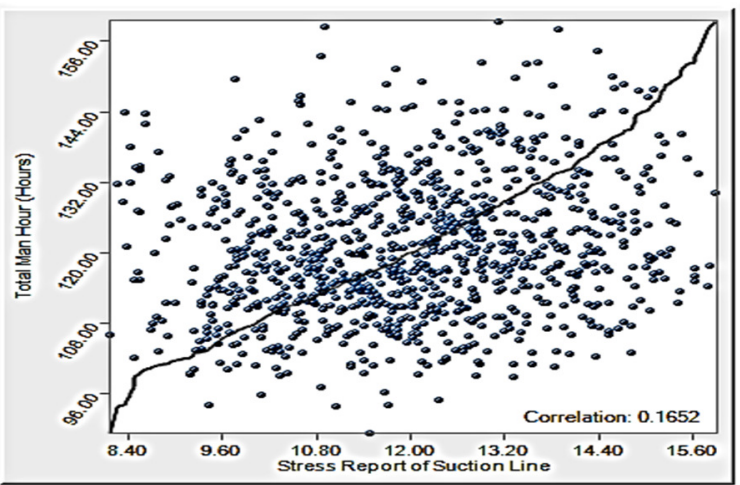

Fig. 5: Correlation between Stress Report of Suction Line and Total Man Hours

\begin{tabular}{|c|c|c|}
\hline \multicolumn{3}{|c|}{$\begin{array}{c}\text { Table 10: Contribution to Variance and Rank } \\
\text { Correlation of Critical Activities }\end{array}$} \\
\hline Critical Activities & $\begin{array}{c}\text { Contribution } \\
\text { to Variance }\end{array}$ & $\begin{array}{c}\text { Rank } \\
\text { Correlation }\end{array}$ \\
\hline Data Collection & $75.9 \%$ & 0.84 \\
\hline Modeling of Suction Line & $5.4 \%$ & 0.23 \\
\hline Modeling of Discharge Line & $5.2 \%$ & 0.22 \\
\hline Analysis of Suction Line & $4.6 \%$ & 0.21 \\
\hline Analysis of Discharge Line & $4.0 \%$ & 0.19 \\
\hline $\begin{array}{c}\text { Stress Report of Suction } \\
\text { Line }\end{array}$ & $3.2 \%$ & 0.17 \\
\hline $\begin{array}{c}\text { Stress Report of Discharge } \\
\text { Line }\end{array}$ & $1.7 \%$ & 0.13 \\
\hline
\end{tabular}

It can be observed that the critical activity "Data Collection" is the most sensitive of all the activities. The risk associated with the activity is "accuracy of the data provided by the client". When this project was awarded, client agreed to provide the relevant data. Since, no risk assessment was done at that time; it was assumed that the data provided will be correct. However, when the project was won and the data from client was received, it was noticed that the data was inaccurate and insufficient to perform the project work. Hence many man-hours were consumed in collecting the specific data from site and validating the provided data. This was not intentional from CLIENT as the CLIENT Side is usually unaware by the type of data required for designing and simulation. It is the duty of the CONSULTANT to check first, if the data that the CLIENT provided is complete and accurate. If the risk assessment was carried out for the project, it would have been identified earlier and the man hour quoted to the client would have been adjusted accordingly resulting in no or less loss of man hours.

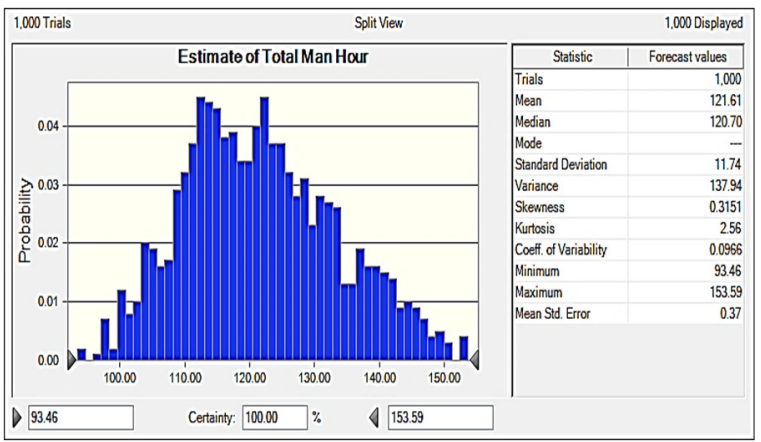

Fig. 6: Estimate of Total Man Hours at 100\% Certainty

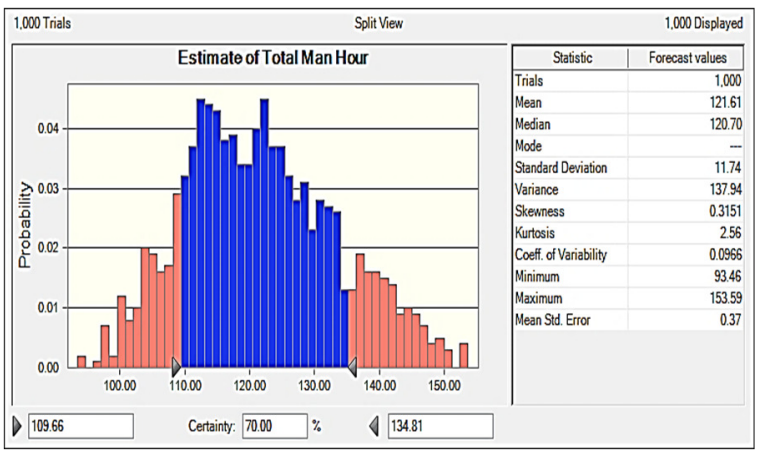

Fig. 7: Estimate of Total Man Hours at 85\% Certainty

Fig. 6 shows that if $100 \%$ possibilities of risks are considered, the total mean man-hour required for the project will be 121.61 hours, whereas the maximum probabilistic time may be 153.59 . However, if a bid is made on the basis of 153.59 hours, the chances of winning the project would be less, whereas mean manhour may seldom occur. Fig 7 shows that if $85 \%$ of all possibilities of risks are considered, the total mean man-hour required for the project will be same and maximum time may be 140.37 . As mentioned earlier, price quoted to the client was on the basis of 85 hours, which indeed resulted in winning the project. However, it was done on account of wasting 50 hours, 
since the project was actually completed in 134.81 hours. This is approximately coinciding with the results obtained though Monte Carlo using $70 \%$ of confidence, which gives 134.81 hours. Now, this percentage $(70 \%)$ is depended upon the criticality of the project and should be decided by an experienced project manager. In many international projects, even a $95 \%$ of confidence is used. However, winning a project on a basis of $95 \%$ is indeed competitive. Whereas, the confidence level of $70 \%$ also impact the Estimated Monitory Value (EMV) and budget contingency, which directly affects the overall budget allocation.

The interpretation of "possibilities" can be understood recalling the Principle of Monte Carlo. Monte Carlo selects a random variable and picks up a value from the range defined for each activity. This creates a scenario. 1000 trails (or possible scenarios) give a value for each activity along with the total man hour. Another point to notice is that the outcomes generated through random variables, forms a normal distribution with the mean "total man-hours" of 121.61 hours and standard deviation of 11.74 hours. Using concepts of standard normal distribution and the formula $\mathrm{Z}=$ $\mu \pm 1.5 \sigma$ yields range of estimate from 109.66 to 134.81 hours. The upper limit closely approximates the actual value in which the project was completed which was 135 hours. Also, $\pm 1.5 \sigma$ corresponds to $70 \%$ of area under the curve for a standard normal distribution, so the interpretation made earlier is validated. The techniques and interpretations used in this model can be used by practitioners to incorporate risk management in the project estimations. Complex models can be made for complex problems in the similar way. The complexity of the problems becomes significantly high when more than one risk affects a single activity. For researchers, this holds prospects for future research to present a model which caters multiple risks acting on a single activity and the interdependency of risks.

\section{CONCLUSION}

Engineering project risks related to the critical activities of small projects have been identified using the surveys and interview techniques. Specific risks related to the small engineering projects are
Australiandetermined and prioritize according to their severity and likelihood. Qualitative and Quantitative Analysis on the risk related to the engineering projects has been applied. Critical activities related to the high severity risks have been identified and the man-hours estimations are performed using the risk quantitative assessment. It has been inferred from the quantitative analysis that the most influencing activity on the manhour estimate is the "Inaccuracy in data" which cause huge estimations variation in such engineering projects. Using the Monte Carlo Simulation based on random variables, it can also be concluded that the certainty of $95 \%$ is not always right specially in competitive environment and engineering projects, where quoting price and man-hours estimates are quite competitive.

\section{REFERENCES}

1. A Guide to the Project Management Body of Knowledge (PMBOK Guide), ${ }^{\text {th }}$ Edition, Project Management Institute, USA, 2017.

2. Akintoye S.; MacLeod M. J., "Risk Analysis and Management in Construction", International Journal of Project Management, Vol. 15, pp. 3138, 1997.

3. Baldry D., "The Evaluation of Risk Management in Public Sector Capital Projects", International Journal of Project Management, Vol. 16, pp. 3541, 1998.

4. Sibinga C. T. S., "Risk Management: An Important Tool for Improving Quality," Transfusion Clinique Et Biologique, Vol. 8, pp. 214-217, 2001.

5. Ward S. C., Chapman C. B., "Risk-Management Perspective on The Project Lifecycle", International Journal of Project Management, Vol. 13, pp. 145-149, 1995.

6. Zhi H., "Risk Management for Overseas Construction Projects," International Journal of Project Management, vol. 13, pp. 231-237, 1995.

7. Hwanga B.-G., Xianbo Z., Tohb L. P., "Risk Management in Small Construction Projects in Singapore: Status, Barriers and Impact", International Journal of Project Management, Vol. 32, No, 1, pp. 116-124, 2014.

8. Keey R.B., "Risk Management: An Australian View", Process Safety and Environmental 
Protection, Vol. 81, pp. 31-35, 2003.

9. Hartono B., Sulistyo1 S. R., Praftiwil P., P.,Hasmoro D., "Project Risk: Theoretical Concepts and Stakeholders' Perspectives", International Journal of Project Management, Vol. 32, No. 3, pp. 400-411, 2014.

10. Hull J. K., "Application of Risk Analysis Techniques in Proposal Assessment," International Journal of Project Management, Vol. 8, pp. 152-157, 1990.

11. Nemuth T., "Practical Use of Monte Carlo Simulation for Risk Management within the International Construction Industry", Proceedings of the 6th International Probabilistic Workshop, Darmstadt, Germnay, November 2627, 2008, 471-482.

12. Rezaiea K., Amalnika M.S., Gereiea A., Ostadib B., Shakhseniaee M., "Using Extended Monte Carlo Simulation Method for the Improvement of Risk Management: Consideration of Relationships Between Uncertainties", Applied Mathematics and Computation, Vol. 190, No. 2, pp. 1492-1501, 2007.

13. Yang W., Tian C., "Monte-Carlo Simulation of Information System Project Performance", Systems Engineering Procedia, Vol. 3, pp. 340345, 2012.

14. Tezukaa S., Murataa H., Tanakab S., Yumae S., "Monte Carlo grid for financial risk management", Future Generation Computer Systems, Vol. 21, pp. 811-821, 2005.

15. Marseguerra M., Zio E., "Optimizing maintenance and repair policies via a combination of genetic algorithms and Monte Carlo simulation", Reliability Engineering and System Safety, Vol. 68, pp. 69-83, 2000.

16. Davies T. C., "The "real" success factors on projects", International Journal of Project Management, Vol. 20, pp. 185-190, 2002

17. Alqadami S. F. H., "Study on Risk Management of Small Foreign Trade between China and Pakistan", Global Journal of Management and Business Research: A Administration and Management, Vol. 18, No. 3, pp. 1-9, 2018.

18. Haseeb M., Bibi A., Qureshi Q. A., Khan I., "Analysis, Perception and Aspects of Risk Management in the Construction Sector of
Pakistan", European Journal of Business and Management, Vol. 6, No. 20, pp. 126-138, 2014.

19. Rehman M. A., Iqbal T., Shakil M., "Identification of Risk Factors associated with Pakistan's Construction Industry-Project Manager Perspective", International Journal of Business and Social Science, Vol. 8, No. 3, pp. 150-157, 2017.

20. Shah M. A., Khan F. Y., Asma, "Risk Management Strategy for Remote Sensing Satellite Project, following the customization of ECSS Standards", Journal of Space Technology, Vol. 1, No. 1, pp. 42-46, 2012.

21. Mubin S., Mubin G., "Risk Analysis for Construction and Operation of Gas Pipeline Projects in Pakistan", Pakistan Journal of Engineering and Applied Sciences, Vol. 2, pp. 2237, 2008.

22. Khan H., "The Contractors' Perception of Risk Management in Pakistan", Proceedings of the Pakistan Academy of Sciences, Vol. 50, No. 3, pp. 189-200, 2013.

23. Hameed A., Woo S., "Risk Importance and Allocation in the Pakistan Construction Industry: A Contractors' Perspective", KSCE Journal of Civil Engineering, Vol. 11, No. 2, pp. 73-80, 2007.

24. Ali T. H., Stewart R. A., Qureshi S., "Evaluating Risk Management Practices in the Pakistani Construction Industry: The Current State of Play", Proceedings of the Fourth International Conference on Construction in the 21st Century (CITC-IV): Accelerating Innovation in Engineering, Management and Technology, July 11-13, 2007, Gold Coast, Australia.

25. Haseeb M., Xinhailu, Bibi A., Rabbani W., "Hazard Risk Analysis and Management in Construction Sector of Pakistan”, International Journal of Economics and Research., Vol. 2, No. 4, pp. 35-42, 2011.

26. Taylor B., Singha G., Ghoshal T., "Research Methodology: A Guide for Researchers", Prentice Hall of India, New Delhi, 2006.

27. Molak V., "Fundamentals of Risk Analysis and Risk Management", CRC Press, USA, 1997. 